\title{
Apical hypertrophic cardiomyopathy: elegant use of contrast- enhanced echocardiography in the diagnostic work-up.
}

\author{
Jeroen WALPOT ${ }^{1}, \mathrm{MD}$; W. Hans PASTEUNING ${ }^{1}, \mathrm{MD}$; Bharati SHIVALKAR ${ }^{2}, \mathrm{MD}, \mathrm{PhD}$ \\ ${ }^{1}$ Department of Cardiology, Admiraal De Ruyter Ziekenhuis, Vlissingen, The Netherlands; ${ }^{2}$ Department of Cardiology, University Hospital \\ Antwerp, Antwerp-Edegem, Belgium.
}

Abstract A 69-year-old woman was evaluated for chest pain complaints. The ECG demonstrated sinus rhythm with deep negative T waves from V2 to V6, in I, aVL and the inferior leads. Transthoracic echocardiography (TTE) showed suboptimal image quality and was nondiagnostic. A repeat TTE study after administration of an echo contrast agent showed normal contractile function with apical hypertrophy. This report contains two messages. First, contrast-enhanced echocardiography is an elegant bedside tool to assess left ventricular apical segments. Secondly, in patients with ECG repolarisation abnormalities without an obvious ischaemic cause, routine echocardiography without contrast may not exclude apical HCM. Definitive exclusion of this important diagnosis requires further imaging such as CMR or contrast echocardiography.

\section{CASE PRESENTATION}

A 69-year-old woman was evaluated for chest pain complaints. Her medical records mentioned a blunt chest trauma in 1996 involving a car accident, with negative anterolateral T-waves on the ECG and presumed LAD-lesion. A coronary angiography was, however, not performed in 1996. The patient was lost in follow-up.

During the present visit the patient consulted for rather atypical chest pain. The ECG demonstrated sinus rhythm with deep negative T waves from V2 to V6, in $\mathrm{I}$, aVL and the inferior leads (figure 1), and was not suggestive of an old myocardial lesion in the LAD perfusion territory.

The transthoracic echocardiographic (TTE) study showed suboptimal image quality and was non-diagnostic (figure 2 panel A and B). A repeat TTE study after administration of an echocontrast agent (Sonoview ${ }^{\oplus}$, Bracco, Milan) showed normal contractile function with

Address for correspondence:

Jeroen Walpot, MD, Department of Cardiology, Admiraal De Ruyter Ziekenhuis, Koudekerkseweg 88, Postbus 3200, 4380 DD Vlissingen, The Netherlands. E-mail: j.walpot@adrz.nl

Received 26 March 2012; accepted for publication 3 April 2012. apical hypertrophy and without evidence of myocardial scarring. Cardiac catheterization revealed angiographically normal coronary arteries and confirmed the diagnosis of apical hypertrophy.

\section{DISCUSSION}

This brief report demonstrates the utility of contrastenhanced echocardiography with suspected cardiac structural abnormalities and suboptimal image quality. Echocardiography has been the first line imaging modality in patients with suspected hypertrophic cardiomyopathy, however, often with poor apical image quality ${ }^{1}$. Echocardiographic studies with transpulmonary intravenous contrast agents suggest that, in the majority of these cases, poor apical endocardial definition leads to false negative reports ${ }^{2-4}$.

In a series of 10 patients with anterolateral $\mathrm{T}$-wave inversion without an obvious pathological cause, routine non-contrast-enhanced echocardiography could not exclude hypertrophic cardiomyopathy (HCM), however, a cardiac magnetic resonance (CMR) scan was diagnostic of apical HCM in all cases ${ }^{5}$.

In Japan, a country with a high prevalence of apical HCM, many researchers have used CMR as a diagnostic tool to exclude apical $\mathrm{HCM}^{6-7}$. CMR in patients suspected of apical HCM has also demonstrated detection 
Fig. 1 The ECG demonstrated sinus rhythm and left ventricular hypertrophy with deep negative $T$ waves from V2 to V6, I, $\mathrm{aVL}$ and the inferior leads.
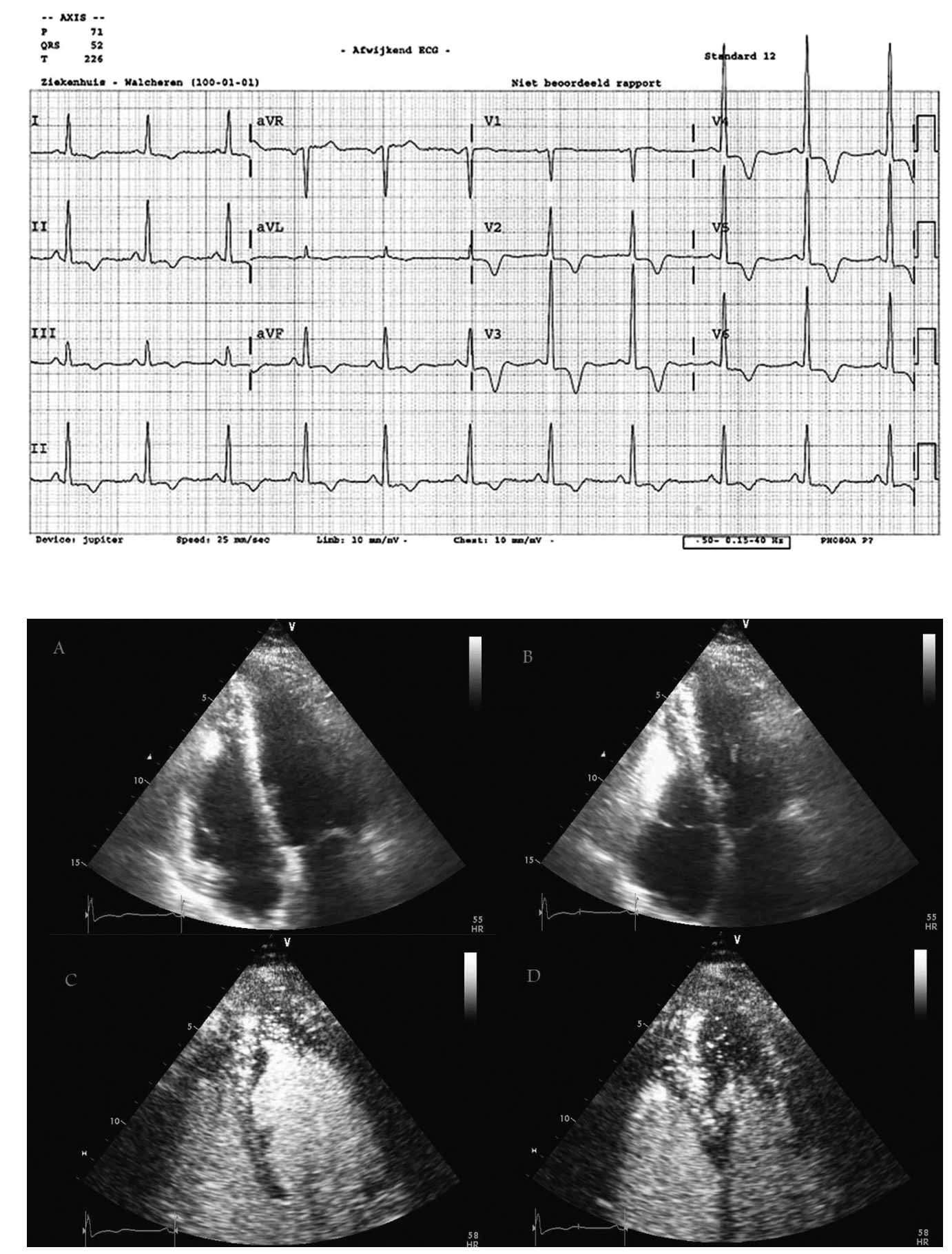

Fig. 2 Panel (a) and (b): TTE 4CH view at end diastole (a) and end systole (b). These TTE images could not document apical hypertrophy. Panel (c) and (d): contrastenhanced echocardiography $4 \mathrm{CH}$ view at end diastole (c) and end systole (d). Note the thickened walls of the apical segments, confirming apical HCM. of apical aneurysms and a peculiar distribution of late gadolinium enhancement, that was not limited to the hypertrophic segments ${ }^{8}$.

\section{TAKE HOME MESSAGES}

This report contains two take home messages. First, contrast-enhanced echocardiography is an elegant bedside tool to assess left ventricular apical segments.
Secondly, in patients with ECG repolarisation abnormalities without an obvious ischaemic cause, routine echocardiography without contrast may not exclude apical HCM. Definitive exclusion of this important diagnosis requires further imaging such as CMR or contrast echocardiography.

CONFLICTS OF INTEREST: none declared. 


\section{REFERENCES}

1. Maron BJ, Spirito P, Green KJ, Wesley YE, Bonow RO, Arce J. Noninvasive assessment of left ventricular diastolic function by pulsed Doppler echocardiography in patients with hypertrophic cardiomyopathy. J Am Coll Cardiol 1987; 10: 733-42.

2. Soman P, Swinburn J, Callister M, Stephens NG, Senior R. Apical hypertrophic cardiomyopathy: bedside diagnosis by intravenous contrast echocardiography. J Am Coll Cardiol 2001; 14: 311-3.

3. Florenciano R, Castillo JA, Molina E, García Urruticoechea P, Egea S, Ortega J. Diagnosis of apical hypertrophic cardiomyopathy using contrast echocardiography. Rev Esp Cardiol 2001; 54: 1336-8 [in Spanish].
4. Ward RP, Weinert L, Spencer KT, Furlong KT Bednarz J, DeCara J, Lang RM. Quantitative diagnosis of apical cardiomyopathy using contrast echocardiography. J Am Soc Echocardiogr 2002; 15: 316-22.

5. Moon JCC, Fisher NG, McKenna WJ, Pennel DJ. Detection of apical hypertrophic cardiomyopathy by cardiovascular magnetic resonance in patients with non-diagnostic echocardiography. Heart 2004; 90: 645-9.

6. Suzuki J, Sakamoto T, Takenaka K, Amano K, Hasegawa I, Shiota T, Amano W, Kawakubo K, Sugimoto T, Nishikawa J. Distribution patterns of hypertrophy at the apical level in patients with giant negative $T$ waves: identification by magnetic resonance imaging.

J Cardiol 1988; 18: 673-82 [in Japanese].
7. Suzuki J, Watanabe F, Takenaka K, Amano K, Amano W, Igarashi T, Aoki T, Serizawa T, Sakamoto T, Sugimoto T et al. New subtype of apical hypertrophic cardiomyopathy identified with nuclear magnetic resonance imaging as an underlying cause of markedly inverted T waves. J Am Coll Cardiol 1993; 22: 1175-81.

8. Fattori R, Biagini E, Lorenzini M, Buttazzi K, Lovato L, Rapezzi C. Significance of magnetic resonance imaging in apical hypertrophic cardiomyopathy. Am J Cardiol 2010; 105: 1592-6. 